\title{
Oxidation Behavior of In Situ Synthesized TiB/Ti Composite in Air Environment
}

\author{
Yexia Qin*, Weijie Lu, Jining Qin and Di Zhang \\ State Key Laboratory of Metal Matrix Composites, Shanghai Jiao Tong University, Shanghai 200030, P.R. China
}

Isothermal oxidation behavior of in situ synthesized TiB/Ti composites has been investigated. Samples of titanium matrix composites reinforced with 0,5 and $8 \mathrm{vol} \% \mathrm{TiB}$ particulates were oxidized at 823,873 , and $923 \mathrm{~K}$ for $300 \mathrm{~h}$ in atmospheric air. Scanning electron microscopy (SEM) with energy dispersive X-ray spectrometry, and transmission electron microscopy (TEM) were used to identify oxidation products and characterize oxide scale morphology. Oxidation was observed to follow parabolic kinetics. Rate of oxidation decreased with the increase of $\mathrm{TiB}$ reinforcements. The oxide scale formed on $\mathrm{TiB} / \mathrm{Ti}$ composites was rutile-type $\mathrm{TiO}_{2}$. No other oxides were observed within the oxide scale. The increased oxidation resistance due to the addition of the in situ synthesized TiB reinforcement was attributed to the improved tendency for the formation of thin and dense oxide avoiding crack and spallation, the strong enough interfacial cohesion and the clean interfacial microstructure between the reinforcements and the titanium matrix alloy.

(Received September 3, 2004; Accepted October 18, 2004)

Keywords: high-temperature; oxidation; titanium matrix composites; oxidation kinetics; in situ formation

\section{Introduction}

Titanium matrix composites (TMCs) possess attractive properties for structural components, such as a high strengthto-weight ratio and a high specific modulus. In addition, they retain the high strength and modulus at elevated temperatures, and have good creep resistance and non-burning characteristics. Consequently, TMCs have a potential for application at elevated temperatures. ${ }^{1,2)}$ In recent years, we highlight a novel in situ process in which traditional ingot metallurgy plus self-propagation high-temperature synthesis (SHS) techniques were used to produce TMCs. ${ }^{3)}$ The formation mechanism of in situ synthesized TMCs has been discussed. ${ }^{4}$ The microstructure and mechanical properties at room temperature and elevated temperature have also been investigated. ${ }^{5-7)}$ The main aim to develop the TMCs is to widen the utilization field at high temperature. In spite of numerous studies on physical and mechanical properties of the in situ synthesized TMCs, an understanding of the oxidation behavior of the TMCs has not yet been fully achieved, which is an important factor for use at high temperature.

Generally speaking, TiB oxidizes according to the following chemical reaction,

$$
\begin{aligned}
& \mathrm{TiB}(\mathrm{s})+7 / 4 \mathrm{O}_{2}(\mathrm{~g})=\mathrm{TiO}_{2}(\mathrm{~s})+\mathrm{B}_{2} \mathrm{O}_{3} \\
& \quad(\text { solid if } \mathrm{T}<723 \mathrm{~K} \text { and liquid if } \mathrm{T}>723 \mathrm{~K})^{8)}
\end{aligned}
$$

Titanium boride, which oxidizes to $\mathrm{TiO}_{2}$ and $\mathrm{B}_{2} \mathrm{O}_{3}$, is not an effective oxidation-resistant material at high temperature, because $\mathrm{TiO}_{2}$ is semi-protective due to its relatively high growth rate and $\mathrm{B}_{2} \mathrm{O}_{3}$ shows little protectiveness due to its high vapor pressure.

The present study deals with oxidation behavior of TMCs in a temperature range 823 to $923 \mathrm{~K}$ in atmospheric in order to provide fundamental knowledge. The isothermal high temperature oxidation behavior of $\mathrm{TiB} / \mathrm{Ti}$ composite was determined. A characterization of the oxidation products, and morphology of the oxide scale were investigated.

*Corresponding author, E-mail: suzieq@sohu.com
Table 1 Compositions and Reinforcements Volume Percentage in TiB/Ti composites.

\begin{tabular}{ccc}
\hline Specimen & Matrix alloy & $\begin{array}{c}\text { Reinforcements } \\
(\text { vol } \%)\end{array}$ \\
\hline TMCs1 & $\mathrm{Ti}$ & $5 \%$ \\
TMCs2 & $\mathrm{Ti}$ & $8 \%$ \\
Pure Ti & $\mathrm{Ti}$ & 0 \\
\hline
\end{tabular}

\section{Experimental Procedures}

On the basis of the former papers, ${ }^{3-6)}$ the commercial pure titanium and TMCs reinforced with $\mathrm{TiB}$ were in situ fabricated by non-consumable vacuum arc remelting. The total volume percentage of reinforcements $\mathrm{TiB}$ was $8 \%$ and $5 \%$, respectively. The reagents used were grade two sponge titanium $(99 \%)$, boron powder $(90 \%$, average particle size: 5 to $7 \mu \mathrm{m}$ ). The compositions of the raw materials used to fabricate the composites and the theoretical volume percentage of the reinforcements are listed in Table 1.

In order to obtain information on the oxidation kinetics, coupons of about $10 \mathrm{~mm} \times 10 \mathrm{~mm} \times 3 \mathrm{~mm}$ were cut out of the ingots. The coupon specimens were polished on a series of $\mathrm{SiC}$ polishing paper, then ultrasonically washed in an acetone bath, dried in air, and weighed before oxidation. This isothermal oxidation studies were carried out in air at a temperature range 823 to $923 \mathrm{~K}$ for a period of $300 \mathrm{~h}$. The performance of the oxidation was evaluated by generating mass-gain data as a function of time.

After oxidation, the oxide scale and oxidation products of the specimens were investigated by scanning electron microscopy (SEM) combined with an energy dispersive X-ray spectroscopy (EDX) unit and X-ray diffraction (XRD) analysis. In order to study the oxidation of TiB reinforcements, transmission electron microscopy (TEM) was used. A Phillips TEM 420 with a maximum acceleration voltage of $200 \mathrm{KV}$ and an EDAX energy dispersive X-ray (EDX) analysis system with windowless detector were available. The TEM samples were prepared by focus iron beam (FIB). 

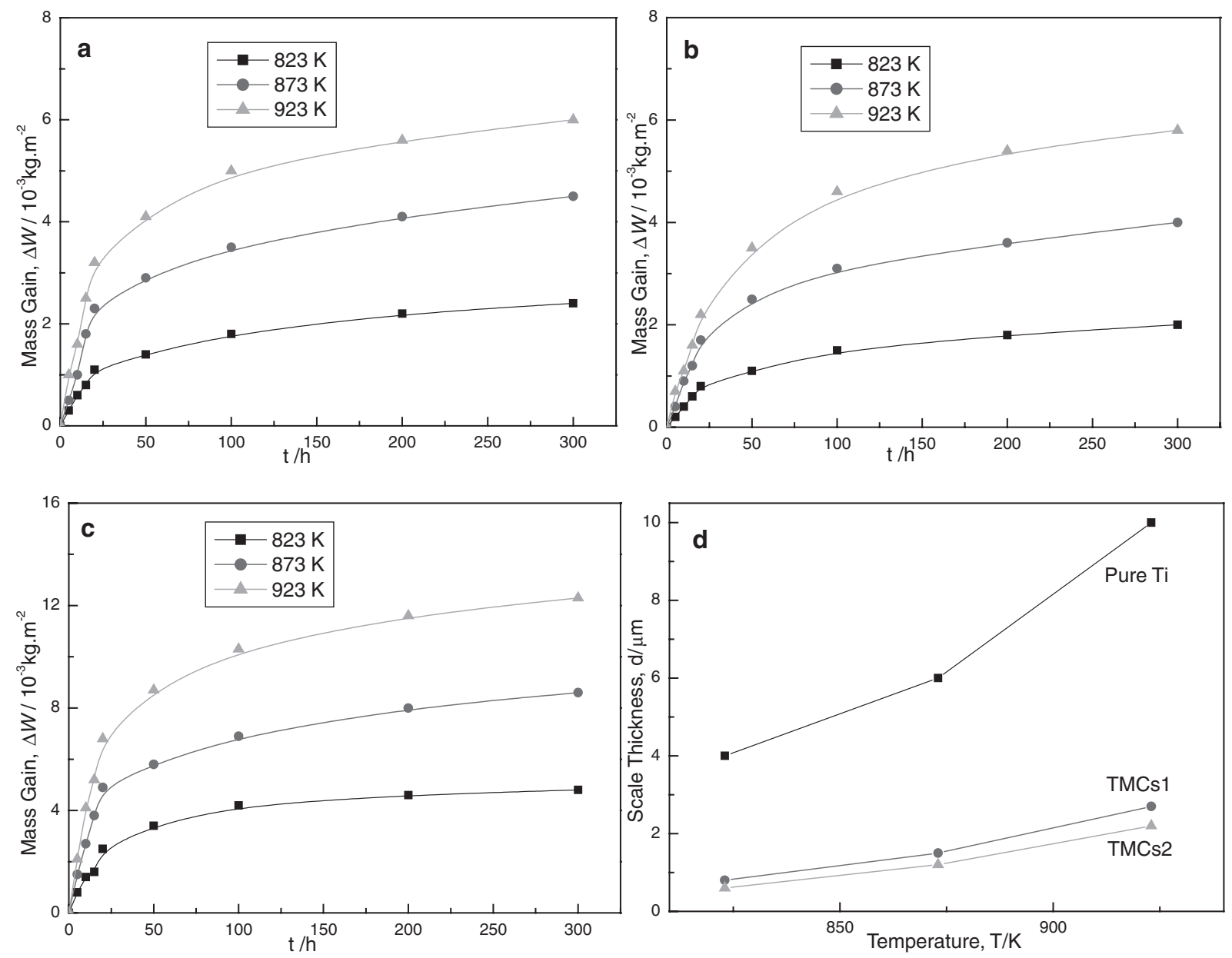

Fig. 1 Mass gain-time relationship of (a) TMCs1, (b) TMCs2, (c) Pure Ti, and (d) measured average scale thickness of TMCs1, TMCs2, and pure Ti after oxidation at 823,873 , and $923 \mathrm{~K}$ for $300 \mathrm{~h}$.

\section{Results and Discussion}

\subsection{Oxidation kinetics}

Figure 1 shows a plot of the mass gain per unit initial surface area versus the oxidation time for pure titanium, TMCs1, and TMCs2 in the temperature range 823 to $923 \mathrm{~K}$. From Fig. 1, it is concluded that oxidation rate of pure $\mathrm{Ti}$ is higher than that of TMCs1 and TMCs2 at all temperatures. Moreover, TMCs2 shows the highest resistance to oxidation at 823,873 , and $923 \mathrm{~K}$.

Usually, the isothermal-oxidation kinetic are expressed as: ${ }^{9)}$

$$
(\Delta m)^{n}=K_{n} t
$$

where $\Delta m, t, n$, and $K_{n}$ are the mass gain per unit area, time, reaction index, and rate constant, respectively. The values of $n$, obtained from the reciprocal of the gradient of the logarithmic plot of $\Delta m$ versus $t$ for a given set of reaction are reported in Table 2. It is apparent that the oxidation kinetics follow a parabolic rate equation at all temperatures for all the specimens.

Since the mass-change curves of $\mathrm{TiB} / \mathrm{Ti}$ composites can be affected by weight loss due to vaporization of $\mathrm{B}_{2} \mathrm{O}_{3}$, as well as weight gain for scaling, ${ }^{10)}$ the thickness of each oxide scale was measured and is displayed in Fig. 1(d). In
Table 2 Calculated Values of the Reaction Index (n) for Isothermal Oxidation as a function of Temperature.

\begin{tabular}{cccc}
\hline \multirow{2}{*}{$\begin{array}{c}\text { Temperature } \\
(\mathrm{K})\end{array}$} & Reaction Index (n) \\
\cline { 2 - 4 } & Pure Ti & TMCs1 & TMCs2 \\
\hline 823 & 2.1 & 2.3 & 2.4 \\
873 & 2 & 2.1 & 2.2 \\
923 & 1.8 & 2 & 2 \\
\hline
\end{tabular}

accordance with the kinetics data shown in Figs. 1(a), (b), and (c), the measurement of average scale thickness showed that the addition of TiB reduces the thickness of oxide scale and improves the oxidation resistance of titanium matrix composites.

\subsection{Metallography}

Typical XRD analysis was undertaken to identify the phases present in the oxide scale. Figure 2 shows the respective XRD patterns of oxide scales formed on TMCs1 and TMCs 2 samples after isothermal oxidation at $823 \mathrm{~K}$ for $300 \mathrm{~h}$. The XRD analyses revealed that the oxide scales formed on TMCs were rutile-type $\mathrm{TiO}_{2}$ at $823 \mathrm{~K}$ for $300 \mathrm{~h}$. No other oxides were present within the oxide scale.

Typical morphology features of the outer surfaces of the specimens after oxidation at $923 \mathrm{~K}$ for $300 \mathrm{~h}$ are shown in 


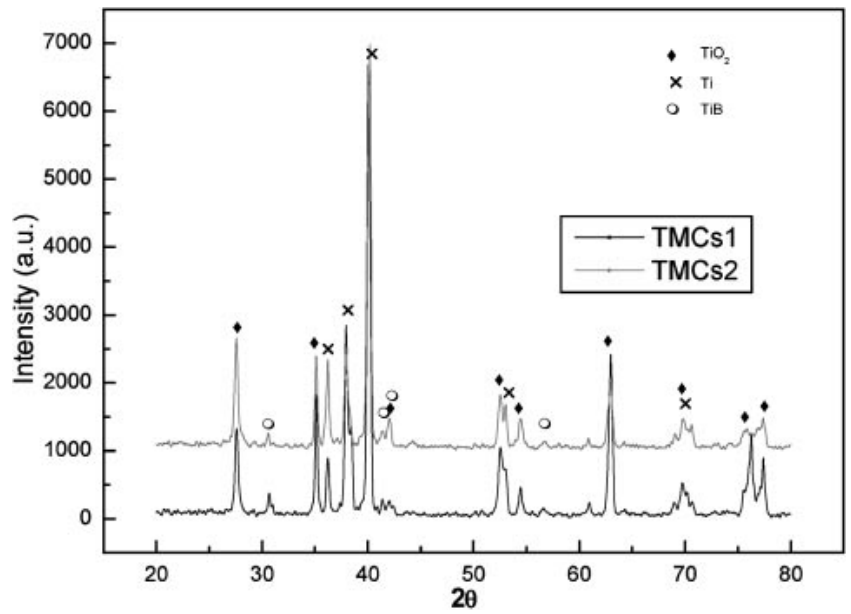

Fig. 2 X-ray diffraction patterns of TMCs1, TMCs2 after oxidation at $823 \mathrm{~K}$ for $300 \mathrm{~h}$.

Fig. 3. Figure 3(c) shows that there are a few cracks on the oxide scales formed on pure titanium, the cracks result from the uneven growth of the oxide scales formed on pure titanium. However, Figs. 3(a) and 3(b) show that the top scales formed on TMCs1 and TMCs2 are continuous and free from cracks. Compared with the size of $\mathrm{TiO}_{2}$ crystals formed on pure titanium, the size of round $\mathrm{TiO}_{2}$ crystallites formed on the TiB/Ti composite is finer. Namely, the addition of TiB will decrease the size of $\mathrm{TiO}_{2}$ crystals. It is of great importance for a practical engineering material used at elevated temperatures. The following reasons can be addressed for this improvement.

Figure 4 reveals the microstructure of a cross section of the oxide scale on TMCs1, TMCs2, and pure titanium after isothermal oxidation at $923 \mathrm{~K}$ for $300 \mathrm{~h}$. Oxide scale formed on pure titanium was observed and shown in Fig. 4(c), it was much thicker (more than $10 \mu \mathrm{m}$ ), porous, and discontinuous. Furthermore, it is apparent that the scale-substrate interface is corrugated (or uneven), indicating that the scale on titanium continues to grow by inward diffusion of $\mathrm{O}^{2-}$ at $923 \mathrm{~K}$. For TMCs2, the oxide scale is very thin, only about $2 \mu \mathrm{m}$ (Fig. 4(a)). The oxide scale of TMCs1 is thicker than that of TMCs2, about $3 \mu \mathrm{m}$ (Fig. 4(b)). It was found that the addition of in situ synthesized $\mathrm{TiB}$ particles led to the increased oxidation resistance and, correspondingly, thin and dense scale formation. EDS analysis revealed that the oxide scale was titanium oxide. XRD results showed the oxide scale was $\mathrm{TiO}_{2}$ (rutile).

In order to reveal the structural details of TiB fiber after oxidation, the microstructures of $\mathrm{TiB}$ were characterized using TEM. Figure 5 shows typical TEM image of TiB after
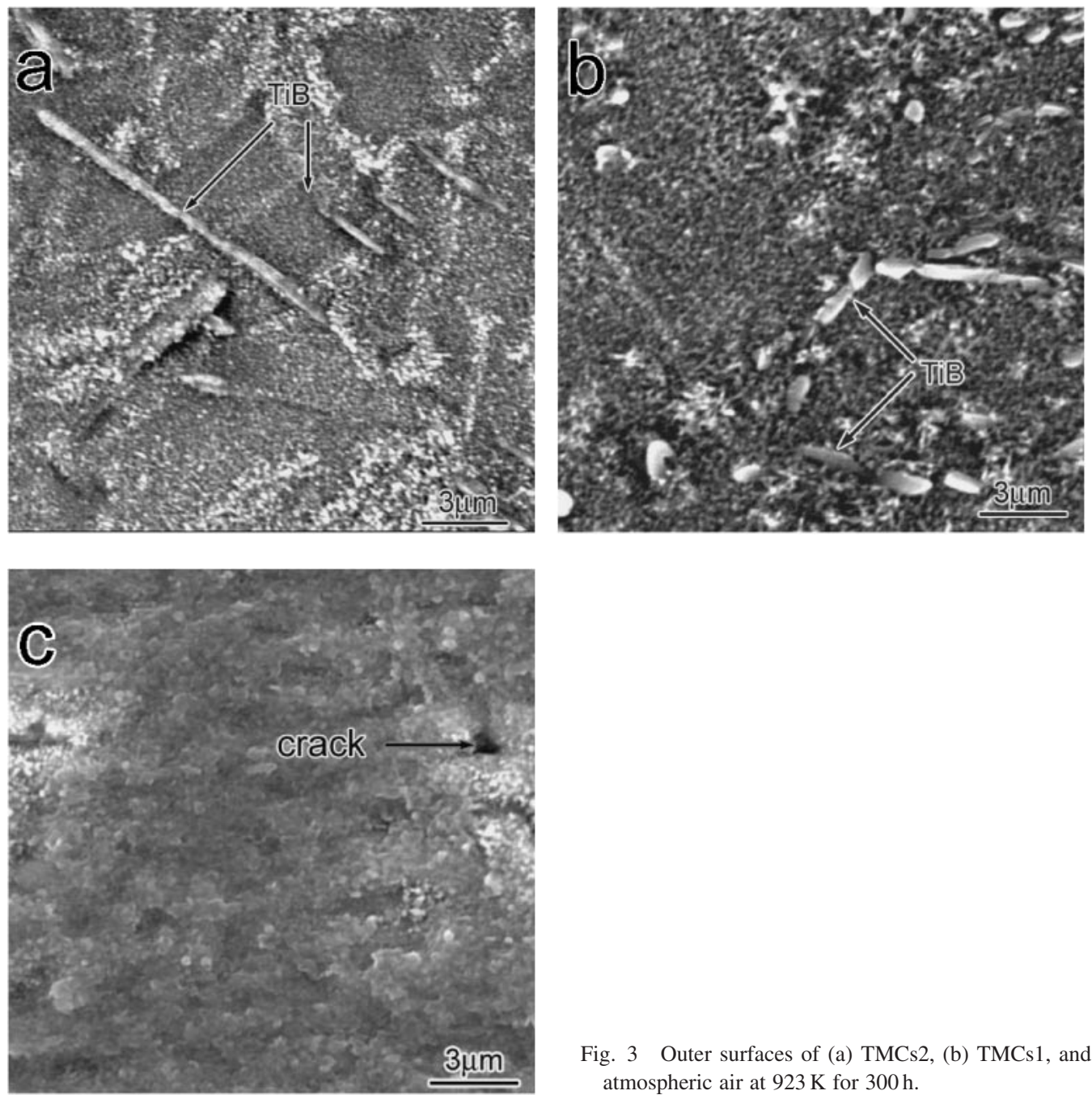

Fig. 3 Outer surfaces of (a) TMCs2, (b) TMCs1, and (c) Pure Ti in atmospheric air at $923 \mathrm{~K}$ for $300 \mathrm{~h}$. 

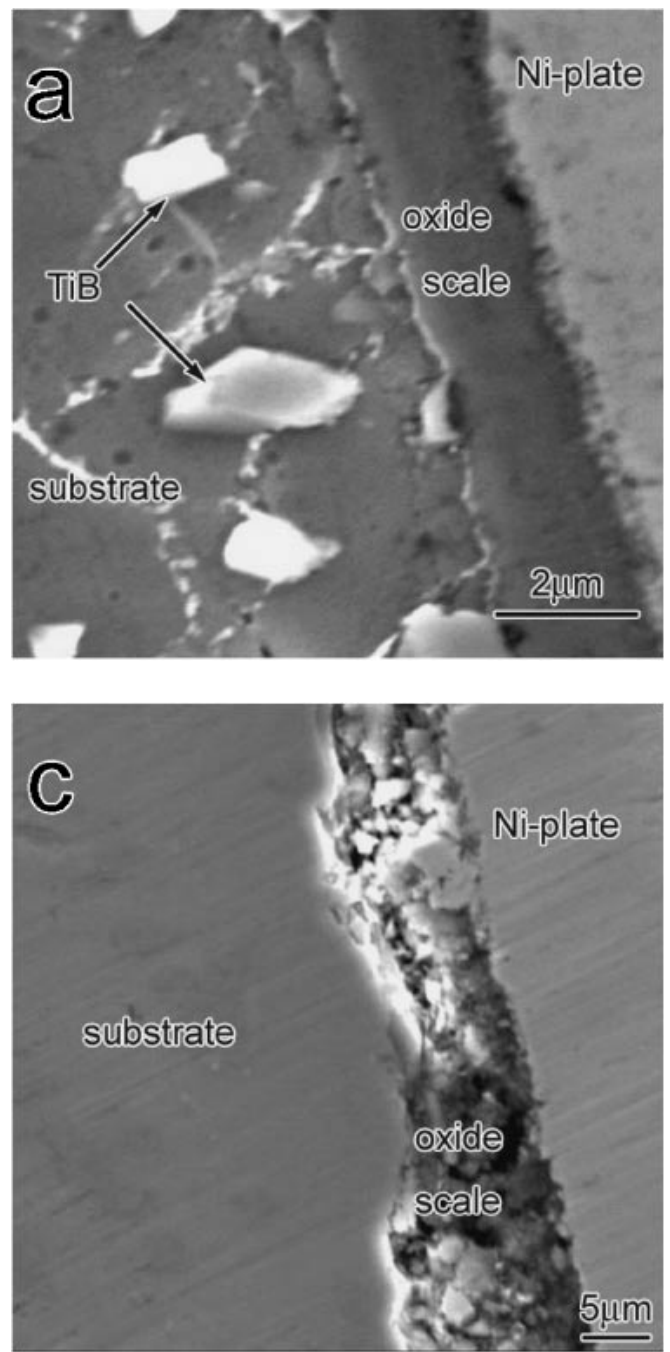

oxidation and the corresponding SAD patterns. Bright field image of TEM reveals that TiB fiber was oxidized partly and the oxide scale consists of a large number of very small grains in the order of $2 \mathrm{~nm}$. The SAD patterns (shown in Fig. 5(c)), which are diffraction rings, as found in the diffraction patterns of polycrystals that have different orientations observed, can be indexed within the limit of error with reflection of $\mathrm{TiO}_{2}$ (rutile). It also can be seen from TEM images that the interface between TiB and the titanium matrix alloy after oxidation is still clean, flat and sharp. There is no interfacial reaction. No changes can be seen on TiB fiber and the interface. The examination of the TiB-oxide interface shows that a porous layer enriched in $\mathrm{TiO}_{2}$ (also the tetragonal rutile) is found after oxidation in this area. This was verified by EDX analysis and electron beam diffraction. The EDX results obtained by spot analysis at the oxide scale and the TiB-oxide interface only shows peaks of titanium and oxygen. So, besides rutile $\mathrm{TiO}_{2}$, there is no nitrides or other oxides.

Oxide scales formed on the composites were composed mainly of very small oxide grains. This is the beneficial impact of the in situ synthesized TiB reinforcements on oxidation. These TiB reinforcements and the high density of grain boundaries could significantly accelerate the oxidation

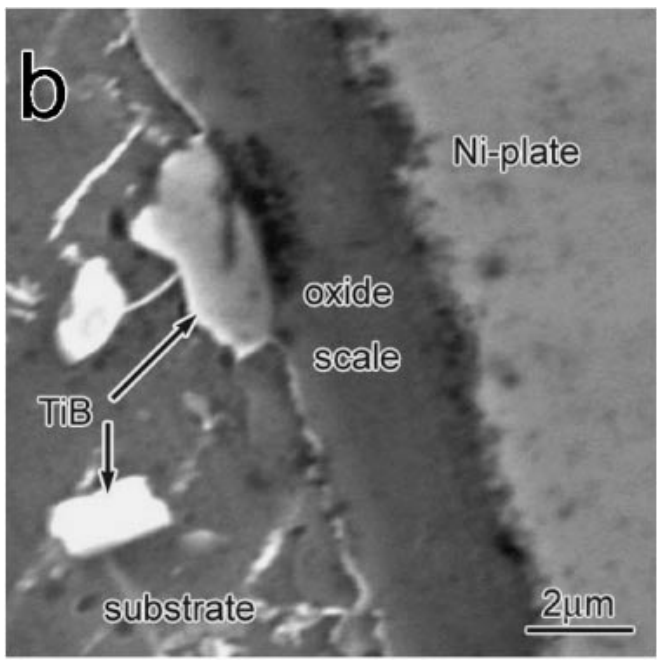

Fig. 4 SEM of oxides on the cross-section of (a) TMCs2; (b) TMCs1; and (c) pure Ti after oxidation at $923 \mathrm{~K}$ for $300 \mathrm{~h}$.

stage, and then shorten the distance between the nuclei. This limits the lateral growth of the oxide, resulting in finer oxide grains. Plastic deformation and creep of the scale are favored by small grain size; therefore, the growth and thermal stresses could be effectively released through scale deformation, avoiding cracking and spallation. ${ }^{11,12)}$

As the size of grain in the substrate is rather small, preferential oxidation in grains or along grain boundaries and phase interfaces could take place on microdimensions, resulting in rugged and rough interface on the composite samples. Some parts of the scale penetrated into the substrate, penning itself firmly to the matrix and keeping the integrity of the interface.

The coefficients of thermal expansion (CTE) of $\mathrm{Ti}$, TiB, $\mathrm{TiO}_{2}$ are $8.2 \times 10^{-6} \mathrm{~K}^{-1}, 8.6 \times 10^{-6} \mathrm{~K}^{-1}, 7.0-8.7 \times 10^{-6}$ $\mathrm{K}^{-1}$, respectively. ${ }^{13)}$ Addition of TiB will decrease the CTE of the whole TMCs. So the CTEs of the scale and substrate are closer with the addition of $\mathrm{TiB}$, it will lower thermal stress. Lower thermal stress also reduces the tendency of scale cracking and spallation.

It is believed that the scales formed on TiB are dense, easy to deform, and have good adherence to the substrate. Therefore, these composites showed excellent spallation resistance. 

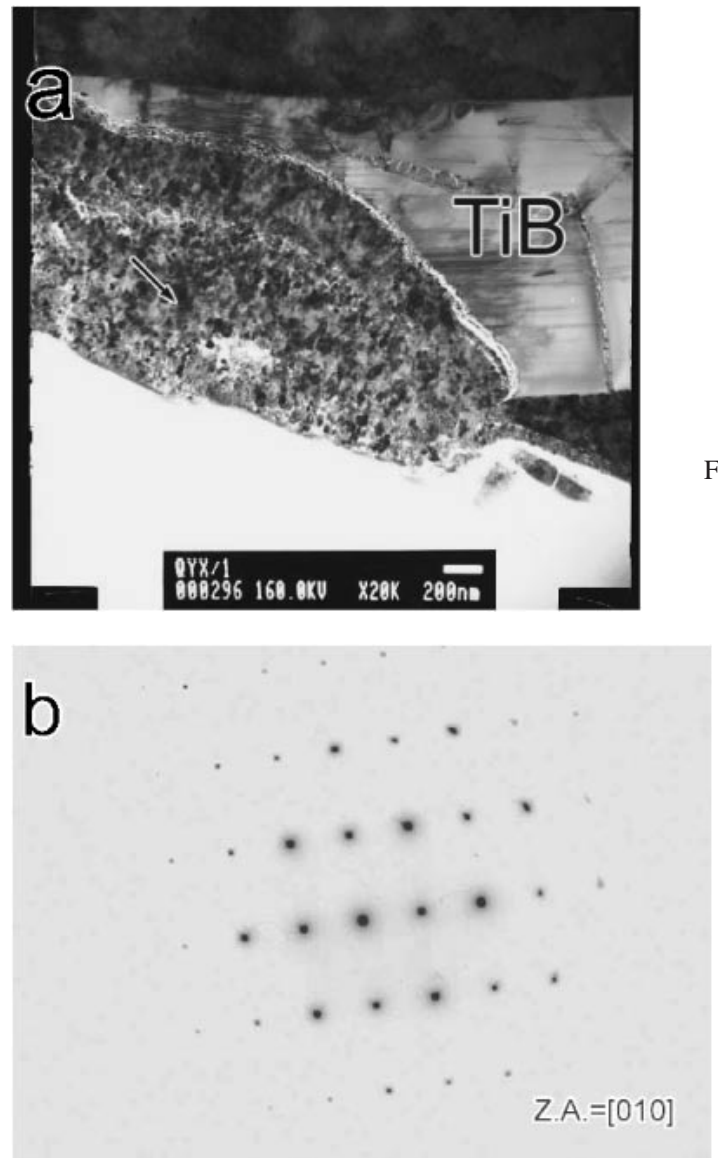

Fig. 5 TEM results of TMCs 2 after oxidation at $923 \mathrm{~K}$ for $300 \mathrm{~h}$ (a) crosssection image around the TiB fiber; (b) SAD pattern of TiB; (c) SAD pattern around the arrow head.

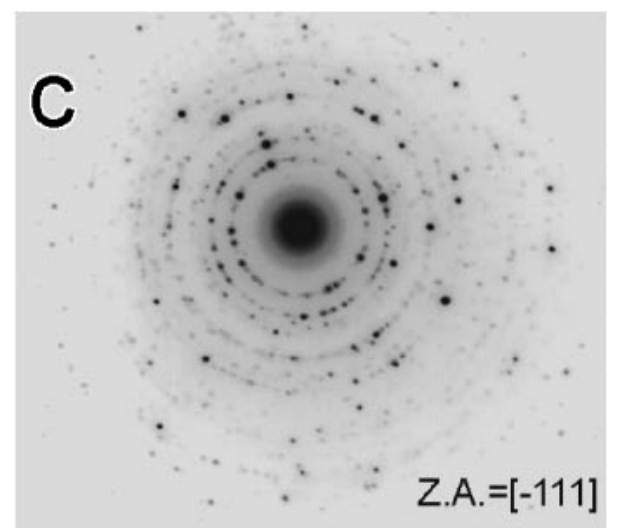

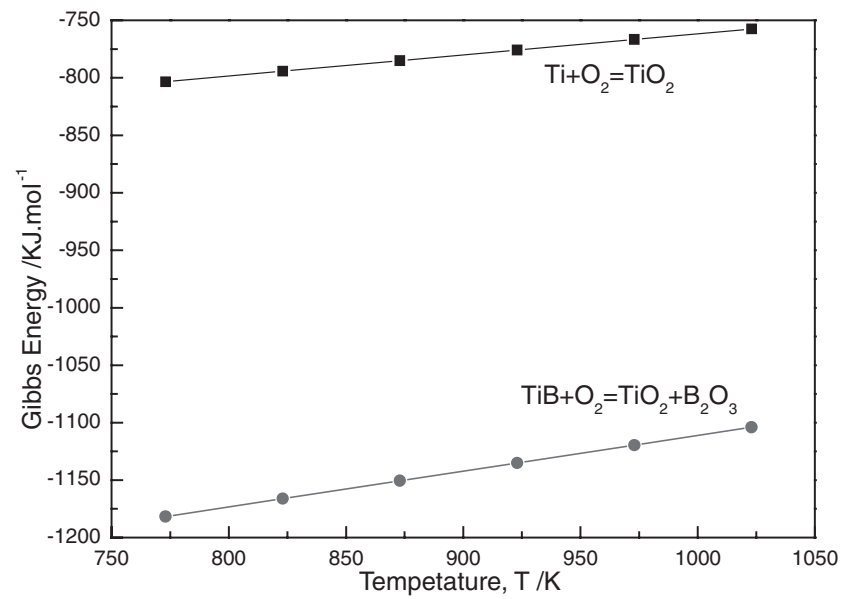

Fig. 6 Comparison of standard Gibbs energies changes as vs. temperature for the oxidation reactions of $\mathrm{Ti}$ and $\mathrm{TiB}$.

\subsection{Mechanism of oxidation}

The respective values of standard Gibbs energies changes $\left(\Delta \mathrm{G}\right.$ in $\left.\mathrm{kJ} \cdot \mathrm{mol}^{-1}\right)$ as a function of temperature $(T)$ of oxidation reactions for $\mathrm{Ti}$ and $\mathrm{TiB}$ are shown in Fig. 6. It shows that the Gibbs free energies are negative in the whole research temperature range (823-923 K), which indicate that these two reactions will take place thermodynamically. The Gibbs free energy of the oxidation of $\mathrm{TiB}$ is lower than that of
$\mathrm{Ti}$, which displays that the oxidation reaction of $\mathrm{TiB}$ has thermodynamic priority to happen at the very first stage of oxidation under the same condition. This difference will result in the preferential oxidation of $\mathrm{TiB}$ in the composite. Therefore, oxidation mechanism of the in situ synthesized $\mathrm{TiB} / \mathrm{Ti}$ composite can be suggested to the nonhomogeneous oxidation because of the higher reactivity of $\mathrm{TiB}$ and $\mathrm{O}_{2}$, and high vapor pressure of $\mathrm{B}_{2} \mathrm{O}_{3}$. However, the addition of TiB will improve the oxidation resistance of the composites. It is attributed to the following factors. Firstly, in situ synthesized TiB fibers with uniform distribution can act as heterogeneous nucleation sites for oxide grains by providing more surface areas to oxygen and reduce the internuclear distance, it will decrease the grain size of $\mathrm{TiO}_{2}$ formed on samples. Prior oxidation of $\mathrm{TiB}$ in the composite will increase oxide nucleation rate during oxidation and allow more rapid formation and partial sealing of oxide scales. Also, in situ synthesized TiB fibers can act as vacancy-annihilation sites, resulting in thin and dense scale formation. Moreover, no scale spallation and cracks were observed on the TMCs. Obviously, dense and compact $\mathrm{TiO}_{2}$ can provide better protection than a porous $\mathrm{TiO}_{2}$ scale. Furthermore, TEM results reveal that the interface cohesion between the reinforcements and the titanium matrix alloy is strong enough and the interfacial microstructure of $\mathrm{TiB} / \mathrm{Ti}$ before and after oxidation is clean. Consequently, in situ synthesized TiB reinforcements can slow down the oxidation rate of the composites. 


\section{Conclusions}

(1) The oxidation kinetics of in situ synthesized TiB/Ti composites at temperatures between $823 \mathrm{~K}$ and $923 \mathrm{~K}$ in air for $300 \mathrm{~h}$ basically follow a parabolic rate law.

(2) The oxidation of the in situ synthesized $\mathrm{TiB} / \mathrm{Ti}$ composite is prior on the TiB reinforcements because of the higher reactivity of $\mathrm{TiB}$ and oxygen, it will lead to the nonhomogeneous oxidation.

(3) $\mathrm{A} \mathrm{TiO}_{2}$-rich layer located at the TiB-oxide interface can be observed. The oxide scale is found to be rutile- $\mathrm{TiO}_{2}$, and no other oxides including $\mathrm{B}_{2} \mathrm{O}_{3}$ can be observed.

(4) The addition of $\mathrm{TiB}$ can improve the oxidation resistance of the composites. The beneficial impacts are attributed to the improved tendency for the formation of thin and dense oxide avoiding crack and spallation, the strong enough interfacial cohesion and the clean interfacial microstructure between the reinforcements and the titanium matrix alloy.

\section{Acknowledgements}

We would like to acknowledge a financial support provided by A Foundation for the Author of National Excellent Doctoral Dissertation of P. R. China under Grant No: 200332, Research Fund of Science and Technology
Commission of Shanghai Municipality under Grant No: 04DZ14002, and ItoYama Foundation.

\section{REFERENCES}

1) D. B. Lee, M. H. Kim, C. W. Yang, S. H. Lee, M. H. Yang and Y. J. Kim: Oxid. Met. 56(3/4) (2001) 215-228.

2) G. Z. Luo: Rare Metall. Mater. Eng. 26(2) (1997) 1-7 (in Chinese).

3) X. N. Zhang, W. J. Lu, D. Zhang, R. J. Wu, Y. J. Bian and P. W. Fang: Scr. Mater. 41(1) (1999) 39-46.

4) W. J. Lu, D. Zhang, X. N. Zhang, R. J. Wu, T. Sakata and H. Mori: Mater. Trans., JIM 41(11) (2000) 1555-1561.

5) Y. X. Qin, W. J. Lu, X. F. Sheng, Z. F. Yang and D. Zhang: Mater. Trans. 44 (2003) 2282-2287.

6) W. J. Lu, D. Zhang, X. N. Zhang, Y. J. Bian, R. J. Wu, T. Sakata and H. Mori: J. Mater. Sci. 36(15) (2001) 3707-3714.

7) W. J. Lu, D. Zhang, X. N. Zhang, R. J. Wu, T. Sakata and H. Mori: Scip. Mater. 44(10) (2001) 2449-2455.

8) D. B. Lee, Y. C. Lee and Deug J. Kim: Oxid. Met. 56(1/2) (2001) 177189.

9) J. Dutta Majumdar, B. L. Mordike, S. K. Roy and I. Manna: Oxid. Met. 57(5/6) (2002) 473-498.

10) E. L. Zhang, G. Zeng and S. Y. Zeng: Scr. Mater. 46 (2002) 811-816.

11) S. A. Kekare, J. B. Toney and P. B. Aswath: Metall. Mater. Trans. A 26 (1995) 1835-1845.

12) B. G. Velasco and P. B. Aswath: J. Mater. Sci. 33 (1998) 2203-2214.

13) A. P. Majid and C. Zweben: Comprehensive Composite Materials, col. 1, (A. Kelly. Elsevier, Amsterdam, 2000) pp. 10-120. 